\title{
Major Histocompatibility Complex Class I Staining Method
}

National Cancer Institute

\section{Source}

National Cancer Institute. Major Histocompatibility Complex Class I Staining Method. NCI

Thesaurus. Code C122845.

An immunohistochemical technique used to detect the presence of class I major

histocompatibility complex antigens in a tissue sample. 